\title{
Java Programming Language
}

National Cancer Institute

\section{Source}

National Cancer Institute. Java Programming Language. NCI Thesaurus. Code C71585.

A platform-independent object-oriented programming language used for writing applets

that are downloaded from the World Wide Web by a client and run on the client's

machine. 